Lima, L.N.M. O turismo, a reinvenção e a espetacularização na Procissão do Fogaréu da Cidade de Goiás (GO). Revista Brasileira de Ecoturismo, São Paulo, v.6, n.1, jan/abr-2013, pp.53-64.

\title{
O turismo, a reinvenção e a espetacularização na Procissão do Fogaréu da Cidade de Goiás (GO)
}

\begin{abstract}
The tourism, the reinvention and transformation in spectacle in the Procession of Fogaréu of Cidade de Goiás (GO, Brazil)
\end{abstract}

\section{Luana Nunes Martins de Lima}

\begin{abstract}
RESUMO
O artigo tece considerações sobre a dinâmica socioespacial instalada na Cidade de Goiás por meio da festa religiosa da Procissão do Fogaréu. Apresenta uma discussão sobre a contribuição da festa na construção da identidade local e na existência de territorialidades, mediante uma pesquisa bibliográfica conceitual e temática, e a observação. Como resultado dessa discussão, é feita uma problematização das transformações e persistências nas práticas socioespaciais dos sujeitos, enfocando a "reinvenção" da festa, sua espetacularização e sujeição ao mercado turístico.
\end{abstract}

PALAVRAS-CHAVE: Procissão do Fogaréu; Identidade Cultural; Território; Turismo.

\begin{abstract}
This article aims to analyze the socio spatial dynamic installed in the Cidade de Goiás through religious party of the Procession of Fogaréu. It presents a discussion about the contribution of the party in the construction of local identity and in the existence of territoriality, through a bibliographic conceptual and theme research, and the observation without participation. As results of this discussion, it's done a problematization of the changes and the persistence in the socio spatial practices of the citizens, focusing the "reinvention" of the party, its transformation in spectacle and merchandise.
\end{abstract}

KEYWORDS: Procession of Fogaréu; Cultural Identity; Territory; Tourism. 


\section{Introdução}

As manifestações culturais têm ocupado um lugar relevante no que tange à valorização da cultura dos lugares, pois apresentam características materiais e simbólicas que representam de alguma forma a própria identidade desses lugares, além de legarem uma singularidade ao território. Por essa razão, entre outras, o estudo das manifestações culturais tem sido apropriado pela Geografia na perspectiva de pensar o território a partir das práticas socioespaciais que nele se inscrevem.

Diante disso, no presente artigo será apresentado o universo cultural da Cidade de Goiás, representado por uma das mais difundidas manifestações culturais e religiosas locais, na qual se evidencia a participação da comunidade na construção da memória identitária da cidade ao preservar e cultivar até os dias de hoje suas tradições como um princípio de vida.

Pela discussão desenvolvida pretende-se conduzir a uma reflexão sobre qual tem sido o papel da Procissão do Fogaréu no processo de afirmação da identidade da Cidade de Goiás e como, na atual etapa de reprodução do capital, essa identidade local é capturada pela lógica do valor de troca, agregando valor a práticas culturais, tornando-as produtos do turismo e do lazer e interferindo direta ou indiretamente no modo de vida da comunidade em questão e nos sentidos que a mesma atribui à festa.

\section{A Procissão do Fogaréu como elemento da identidade local}

De acordo com Silva (2001), a Cidade de Goiás, Patrimônio Histórico da Humanidade desde 27 de junho de 2001, título conferido pela Organização das Nações Unidas para Educação, Ciência e Cultura (UNESCO), conserva mais de $80 \%$ de sua arquitetura barroco-colonial original, possuindo diversos elementos que marcam a identidade local, como os muros de rochas feitas por escravos no século XVIII, as igrejas, os mosteiros e os cruzeiros no cume dos morros, os casarios, os palácios, os museus que dão guarida a documentos e pertences dos bandeirantes colonizadores, os becos e as ruas.

Considera-se também como marcos identitários a presença das doceiras, a culinária representada pelo empadão goiano e pelo arroz-com-pequi, os licores produzidos com frutos típicos do cerrado, os quadros de areia de Goiandira Couto, a figura de Cora Coralina (cuja casa se tornou museu) e suas poesias que homenagearam Goiás e sua gente.

Além disso, a cidade situa-se no entorno da Serra Dourada e possui grandes áreas preservadas do cerrado. A cidade é conhecida também por sua festividade religiosa e pela criação, no final dos anos 90, do Festival Internacional de Cinema e Vídeo Ambiental (FICA), que atraem milhares de turistas todos os anos.

A principal festa religiosa na Cidade de Goiás é a Procissão do Fogaréu na Semana Santa, a qual, segundos dados do portal da Cidade de Goiás, foi introduzida na antiga capital pelo padre espanhol João Perestelo de Vanconcelos Espíndola, por volta de 1745. Esta manifestação se apresenta como um referencial, símbolo da cultura vilaboense e goiana.

Todos os elementos citados, tanto os de caráter material como aqueles que se ex- 
pressam simbolicamente dão forma à paisagem local e ordenam o território. A paisagem e o território, então, "são dimensões marcadas por elementos patrimoniais, signos da trajetória da sociedade que ativam a memória e situam os grupos definindo suas identidades" (ALMEIDA; VARGAS; MENDES, 2011, p. 33).

Para Castells (2006), a construção de identidades forma-se a partir do que é fornecido pela história, geografia, biologia, instituições produtivas e reprodutivas, pela memória coletiva e por fantasias pessoais, pelos aparatos de poder e revelações religiosas. Entretanto, o autor ainda afirma que "esses materiais são processados pelos indivíduos [...], que reorganizam seu significado em função de tendências sociais e projetos culturais enraizados em sua estrutura social, bem como em sua ótica de tempo/espaço" (CASTELLS, 2006, p.23).

Apreender essas relações e significações que os indivíduos estabelecem na construção de identidades implica em considerar o espaço em que vivem os mesmos e reconhecer que a construção material e a construção simbólica do espaço se articulam dialeticamente, resultando na formação de territórios.

Almeida (2008, p. 58-59), considera o território, antes de tudo, como "uma convivialidade, uma espécie de relação social, política e simbólica que liga o homem à sua terra e, simultaneamente, estabelece sua identidade cultural". E na relação da identidade social com o território situa-se a territorialidade, que para a autora, remete tanto às questões de ordem simbólico-cultural como também ao sentimento de pertencimento a um determinado território. Nesse sentido, ela ressalta que "a cultura, como dimensão de operações simbólicas, adere às paisagens e as constrói, conformando-as mediante vivências e significações".

É nas sociedades mais tradicionais que "as ligações entre os grupos humanos e o espaço onde eles moram são mais diretas e mais fortes", conforme enfatiza Claval (2008, p. 17). Na medida em que as sociedades se modernizam, as formas de territorialidade, embora não desapareçam, tendem a sofrer mudanças, como demonstrado em estudos mais recentes. Isso ocorre também com a turistificação de lugares, como será apresentado mais adiante.

As festas, como a Procissão do Fogaréu, se constituem como um importante elemento na construção de identidades e de tradições manifestas em práticas culturais. Bezerra (2007a, p. 4), ao destacar a função da festa no processo de (re)afirmação das identidades locais, faz a seguinte consideração:

A festa, neste contexto das representações, assume um papel importante, pois seu caráter tanto material quanto simbólico contribui para que ela assuma a função de produtora de uma identidade da cidade." [...] Neste cenário das imagens e das representações sobre a cidade, a festa, tem ganhado uma centralidade, pois seu poder de impressionar, seu caráter estético e ao mesmo tempo simbólico, tem contribuído para que ela assuma o papel de representação da identidade local. 
O destaque da Procissão do Fogaréu como referência identitária em Goiás se insere num contexto nacional. Na década de 1970 houve uma mudança na ideia que se tinha de Patrimônio, que deixou de ser apenas o material, agregando também o imaterial. Mariani (1999) afirma que a partir dessa década, as manifestações populares, culturais e artísticas, passam a figurar entre o conjunto de bens representativos da identidade nacional, e selecionados pelo Instituto do Patrimônio Histórico e Artístico Nacional (IPHAN). Essa ideia foi sendo cada vez mais arraigada nas populações das cidades históricas, fortalecendo seus laços identitários a partir de suas manifestações culturais.

No caso da Cidade de Goiás, a Procissão do Fogaréu, bem como seus símbolos e signos estão intimamente atrelados ao cotidiano dos moradores, como se já fizesse parte de suas vidas. A construção da identidade local, no uso dessa festa religiosa, ultrapassa a noção materializada da festa. Mas como a própria identidade está em constante processo de construção, a forma de apropriação e de sentidos atribuídos à festa também são múltiplos e relacionam-se ao espaço e ao tempo. Sobre isso, Almeida, Mendes e Vargas (2011, p.27), consideram que "o espacial, ao ser permeado por distintas temporalidades, gera, ininterruptamente, novas configurações, que, certamente, desencadeiam persistências e/ou reconfigurações identitárias".

\section{Procissão do Fogaréu: as partes da celebração}

A Semana Santa da Cidade de Goiás é uma celebração religiosa tradicional que se assemelha a outras festas no Brasil, em termos de magnitude e repercussão midiática. A festa começa à meia noite da quarta-feira da semana santa, de acordo com o calendário católico, quando as encenações sobre a Paixão de Cristo movimentam a comunidade, os organizadores e os turistas, que acompanham o ritual com devoção e curiosidade. A celebração envolve a encenação das principais passagens bíblicas que antecedem a crucificação de Cristo pelas ruas da Cidade de Goiás.

De acordo com as informações disponibilizadas no portal da Cidade de Goiás ${ }^{1}$, a Procissão do Fogaréu inicia-se com uma representação do caminho que os romanos percorreram na "caça inquisitorial" a Cristo. Quarenta homens encapuzados com indumentárias coloridas, denominados "farricocos", que representam os mantenedores da ordem (perseguidores), carregam tochas acesas entre as ruas escuras ao som dos tambores da fanfarra. Habitualmente, eles partem da Igreja da Boa Morte e andam descalços pelas veIhas ruas da antiga Vila Boa. Fazem sua primeira parada na porta da Igreja Nossa Senhora do Rosário, diante dos "restos da última ceia". Neste momento, o rufar dos tambores diminui, sendo realizada a primeira pregação (homilia) religiosa. Em seguida, os farricocos acompanhados pela multidão, seguem para a Igreja de São Francisco de Paula, que representa o Monte das Oliveiras. Um dos farricocos, portando um estandarte de linho pintado em duas faces (obra do artista plástico Veiga Valle, atualmente substituído por outro, obra de Maria Veiga) que simboliza Jesus Cristo, anuncia a prisão do Salvador ao som de um clarinete executado por outro farricoco, quando então é feita a última pregação (homilia), único ato litúrgico realizado pelo Bispo Diocesano, no pátio da Igreja de São Francisco de Paula, contando a prisão de Jesus. Logo após a pregação, o povo acompanha os farricocos de volta à Igreja da Boa Morte, onde se encerra a procissão. 
Durante a procissão, a companhia de energia suspende a iluminação pública. $O$ percurso é iluminado pelas quarenta tochas levadas pelos farricocos e por outros archotes distribuídos entre o público que acompanha os mesmos.

Por muitos anos, o Coral Solo, criado na década de 1970 pelos irmãos Curado e considerado o principal conjunto vocal da cidade, entoa motetos em latim durante a procissão. São cantadas três peças dos Motetos dos Passos, no início (Exeamus), na parada do Rosário (Domine) e após a prisão de Cristo (Pater). A fanfarra, que consiste em tambores tocando marchas rápidas, foi introduzida por volta de 1965, com fim de se fazer silêncio.

A figura dos farricocos retoma as cerimônias espanholas litúrgicas e paralitúrgicas da Semana Santa, como as de Toledo e Sevilha, e ao período da inquisição. Os trajes são de origem medieval, os quais eram comumente utilizados por penitentes, que podiam, dessa forma, expiar seus pecados sem terem que revelar publicamente sua identidade. Originalmente, nesta cerimônia só os homens tinham permissão para participar.

A Procissão do Fogaréu é repleta de detalhes e os elementos nela presentes, como a escuridão, as tochas acesas, os homens encapuzados, entre outros, criam um clima medieval assustador e excitante, onde a superstição também está presente. Existem crenças populares de que o demônio estaria solto pelas ruas da cidade nesta noite, aterrorizando a todos e, principalmente, as crianças que iam para a cama mais cedo. Há também outras crendices relacionadas à presença de personagens do folclore brasileiro, como lobisomem e mula-sem-cabeça, principalmente na zona rural.

Ainda segundo os dados disponíveis no site oficial da cidade, a procissão dura cerca de uma hora e meia e é acompanhada por cerca de 10 a 15 mil pessoas todos os anos, conforme a média divulgada pela Polícia Militar (PM). A preparação da festa começa um dia antes, com o reconhecimento do trecho a ser percorrido pelos integrantes, marcando o lugar de cada um no trajeto e nas paradas. No dia da procissão, às 15 horas, é realizado o preparo das tochas, e às 19 horas, o último ensaio antes do início da Procissão.

Os eventos que se seguem após a Procissão do Fogaréu, na quinta e na sextafeira da Semana Santa são, respectivamente, a representação do Lava-pés e a Paixão de Cristo. Na Quinta-Feira Santa é celebrada a missa do Lava-pés e a Santa Ceia na Catedral, na Igreja Nossa Senhora do Rosário e na Igreja Santa Rita. Na Sexta-Feira Santa as atividades começam às 6 horas, com a realização da Via Sacra, da Catedral ao Morro do Cruzeiro e, às 15 horas, a comemoração da Cruz na Catedral. Na sexta-feira à noite são realizados o canto do perdão, na Igreja São Francisco de Paula e o Descendimento da Cruz, na Praça do Chafariz. O Sábado Santo é marcado por silêncio, retiro e orações, com penitência comunitária e individual, às 19 horas, na Catedral. No Domingo de Páscoa, as atividades se encerram com missas de manhã e à noite.

Outro exemplo de festividade que remonta a encenação da Paixão de Cristo na Sexta-Feira Santa, pertinente mencionar por sua contextualização, é realizado há onze anos pela comunidade de Quixaba, em Aracati, no litoral leste do Ceará, a 150 quilôme- 
tros de Fortaleza. De acordo com informações disponibilizadas no site do Serviço Brasileiro de Apoio às Micro e Pequenas Empresas (SEBRAE), a dramatização reúne cerca de 300 atores, com elenco formado principalmente por moradores da localidade e todos os anos atrai um público médio de 7 mil pessoas, entre moradores da região, turistas estrangeiros e de vários estados do Brasil.

Na cidade-teatro Nova Jerusalém, no município de Brejo da Madre de Deus em Pernambuco, a Semana Santa com a encenação da Paixão de Cristo tem sido alvo das campanhas promocionais de agências turísticas. O elenco reúne atores regionais, mas também intérpretes de renome nacional nos principais personagens, o que reforça o sentido de espetáculo da festa.

Além de uma expressão de religiosidade e da cultura popular brasileira, as encenações da Semana Santa representam uma atração turística. Há muitos anos essas festas tradicionais atraem milhares de turistas do Brasil e do exterior. Em Goiás e no Ceará, o SEBRAE apoia espetáculos que fazem parte dessa tradição cristã, patrocinando confecção de camisetas, bonés, entre outros; disponibilizando ônibus para uso da organização; realizando filmagens a fim de divulgação; e fortalecendo o empreendedorismo em agências de viagens, hotéis, pousadas e comércio local (artesanato, alimentação).

Já consta na Cidade de Goiás a existência de políticas da administração local, bem como instituições de ensino e órgãos que se dedicam à divulgação e à publicização da Procissão do Fogaréu. Vale ressaltar que o Grupo Focal é formado por representantes da comunidade que apoiam a sua realização e a Organização Vilaboense de Arte e Tradição (OVAT) é a executora da festa religiosa.

\section{Tendências do mercado: reinvenção e espetacularização}

Alguns elementos importantes podem ser identificados a fim de compreender a dinâmica instalada na cidade por meio da Procissão do Fogaréu, a saber: a dimensão territorial e cultural da Procissão do Fogaréu e sua correlação com o espaço em que ocorre e com o contexto social, levando-se em conta aspectos da própria geografia local; as políticas culturais e o papel de órgãos e organizações na representação da cultura na cidade; a atuação local da mídia; e, principalmente, o desenvolvimento do turismo, que se estabelece como principal atividade econômica na cidade.

É importante ressaltar que vivemos em um tempo em que tudo é cultural e tudo pode se tornar patrimônio, muitas vezes, por razões políticas, particularistas e mercantis. Costa (2010) parte de uma concepção simbólica de cultura enquanto um padrão de significados incorporados nas formas simbólicas e materiais, para esclarecer como a indústria cultural, por meio dos processos contemporâneos de globalização econômica, se relaciona com as localidades e as formas culturais num processo que resulta em sua intensa mercantilização. Sobre essa cultura materializada ou não no território, surge "a tendência dialética da construção e da desconstrução dos lugares, da revaloração da paisagem, na sociedade contemporânea permeada pela própria reprodução do dinheiro no território, produzindo o real espetáculo da sociedade" (p. 88).

O turismo, então, se apresenta como uma nova tendência de apropriação do espa- 
ço estabelecendo-se nos lugares na busca por assegurar uma visibilidade e um conjunto de práticas que revalorizem esses lugares.

A atividade turística deve ser analisada como um fenômeno econômico-cultural moderno dinamizado por uma sociedade de consumo e, portanto, essa análise deve se estender para além da dimensão material do espaço. A produção, a reprodução, a fragmentação e a homogeneização do turismo no espaço por meio das novas espacialidades da vida social, material e simbólica, por vezes produzem lugares turísticos subordinados aos atores hegemônicos, gerando uma desordem desmedida na estrutura social.

O turismo surgiu na Cidade de Goiás como uma proposta econômica de inclusão social, contribuindo para novas perspectivas de valorização da vida, para o usufruto de produtos culturais e para uma melhor distribuição de renda. Contudo, o mesmo está associado a uma economia de mercado que exclui parcelas significativas da população de participarem do crescimento econômico e social, além disso, transforma as manifestações culturais, as práticas de fé, crenças, saberes e outros elementos da cultura popular em mero espetáculo a ser assistido, filmado e levado como memorial de um lugar exótico visitado.

Serpa (2007), ao tratar sobre o conceito de "espetacularização", analisa alguns casos no estado da Bahia que apontam para esse fenômeno, nos quais ocorre o nascimento da cidade da "festa-mercadoria". Nela, a história e a tradição dos lugares são industrializados, há requalificações e revitalizações urbanas e, ainda, a inserção no mercado globalizado das imagens turísticas e dos lugares-espetáculo.

Novas formas de ação na gestão de bens culturais surgem todos os dias na tentativa de se articular o patrimônio cultural, material ou imaterial, ao turismo. Infelizmente, nem todas essas ações favorecem a inclusão da comunidade local, que preservou e guardou o bem histórico.Um turismo responsável é aquele voltado primeiramente para a comunidade, gerando novas perspectivas de melhoria da qualidade de vida a partir da utilização comprometida desse bem patrimonial.

Em uma abordagem sobre a disputa do território do Cerrado, Chaveiro (2008b) sintetiza como alguns atores que participam dessa disputa transformam a cultura do cerrado e sua potencialidade em negócio para lazer e turismo. Em suas palavras: "As festas, as temporadas e eventos criados, dessa maneira, se ajustam à criação de um desejo baseado na performance, no narcisismo, na corpolatria, na autoajuda, na institucionalidade religiosa e outros" (p. 85-86). Assim, adequa-se a cultura local à demanda pelo consumo.

Ainda sobre essa atuação mercadológica, Santos (2008, p. 130) afirma que "a identidade pode ser evocada como tradição" e "na perspectiva histórica, ela pode se manifestar como sendo enraizada no lugar, sendo entendida como pertencimento, e no conjunto pode ser uma reação às forças do mercado, mas pode ser também uma resposta a elas". Baseando-se nessa afirmação, há também a necessidade de se considerar a festa como é vista e sentida pela própria comunidade local, ou seja, sua percepção sobre a forma de conexão da festa com a história e com a construção identitária da cidade, e que tipos de impactos ou contribuições o turismo expressa para essa comunidade.

Faz-se necessário também uma investigação do papel que a mídia desempenha 
com relação à festa em questão. Nas palavras de Bezerra (2007b, p. 70), é preciso "situar esses entrelaçamentos entre festa, cidade e identidade nesse momento histórico da dinâmica capitalista em que o uso da imagem tem assumido uma centralidade, resultando assim no processo de espetacularização da sociedade". Ainda segundo a autora, esse uso da imagem está relacionado ao consumo, pois a manipulação do gosto e da opinião faz acelerar o tempo de giro na produção da volatidade. " $E$ a partir desse quadro [...] que a publicidade e as imagens da mídia passaram a ter um papel mais integrador nas práticas culturais, tendo assumido agora uma importância muito maior na dinâmica de crescimento do capitalismo" (2007b, p.70).

Em abordagem ao impacto cultural dos meios de comunicação no mundo moderno, Thompson (1998) defende que o aspecto identificador da tradição não foi eliminado pelo desenvolvimento das sociedades modernas. A exposição da mídia não provoca o abandono da tradição; quando muito, remodela a tradição, expandindo-a e consolidando-a. A formação e a transmissão das tradições tornam-se cada vez mais dependentes das formas de comunicação que perderam o caráter face-a-face, pelos variados meios de comunicação. Com isso, algumas consequências são destacadas pelo autor: 1) A adoção de uma fixação do conteúdo simbólico nos produtos da mídia para garantir a permanência temporal, o que geralmente não existe nos intercâmbios de comunicação face-a-face. 2) A transmissão da tradição se separa dos indivíduos com quem se interage no cotidiano, adquirindo certa autonomia e autoridade própria que permitem que as crenças e valores implicados a essa tradição persistam independentemente deles. 3) A ocorrência do desenraizamento dos lugares espaciais dentro dos quais os indivíduos viviam, libertando as tradições dos limites impostos pela transmissão oral peculiar da interação face-a-face. Isso, porém, não significa que a mídia destrói a conexão entre tradições e unidades espaciais. Ao contrário, as tradições são deslocadas sem perderem sua territorialidade, ou seja, são remodeladas para serem ligadas a diversas unidades territoriais, cujos limites ultrapassam os da interação face a face.

A respeito da última consequência apontada por Thompson (1998), é evidente que a Procissão do Fogaréu, em todo seu conteúdo simbólico, não se desvinculou ou se desenraizou da Cidade de Goiás. Contudo, a ação da mídia produziu o efeito de tornar a festa algo não mais de participação particular da cidade, mas voltada principalmente para os turistas.

Almeida (2004) trata do contraste entre desenvolvimento turístico e desenvolvimento local, enfatizando que a construção do espaço turístico se dá com a desconstrução do lugar. Assim, as transformações do ambiente e das relações sociais, bem como do patrimônio cultural que antes permitiram a existência desse lugar são em "função do outro", para a conservação do atrativo e não para a valoração local, sendo esses elementos desterritorializados para serem exclusivamente revalorizados pelo turista.

O lugar deve corresponder às imagens e ao imaginário daquele que é turista, o que supõe um desvio do uso tradicional do lugar. "É o olhar extasiado, do "outro", do forasteiro, admirando paisagens que atribuem valor, [...] parte de seu próprio conjunto de valores e que, associado aos interesses do lucro, pela mídia, postais e guias de viagens, inventam o lugar turístico" (ALMEIDA, 1998, p.125).

É possível observar a supervalorização da Procissão do Fogaréu como espetáculo "chave" da Cidade de Goiás. A despeito disso, não há igualmente o reconhecimento de uma cultura popular local. Afinal, as pessoas que assistem às encenações, representações e mis- 
sas desconhecem, em grande parte, a história de vida dos moradores, a história da festa como prática da cultura vilaboense. Assim, elas não compreendem o sentido dos rituais e os valores, consumindo apenas as imagens.

Além disso, a espetacularização que permeia a festa gera uma grande preocupação com a imagem e requer esforços cada vez maiores dos participantes e da comunidade em geral para atender um público exigente.

Ao longo dos anos o uso mercadológico das manifestações culturais na cidade tendem sempre a transformá-las gradativamente, seja aumentando componentes nas representações, seja incorporando novos elementos aos rituais, ou ainda modificando as indumentárias, os instrumentos, etc, dando aos mesmos, novos padrões de destaque. Primordialmente, na representação da paixão de Cristo da Procissão do Fogaréu, havia doze farricocos. Décadas mais tarde passou-se para vinte, atualmente são 40 . Outro relevante aspecto observado in loco é a comercialização acentuada de souvenir e artesanato que representam a festa em vários comércios de artesanato.

Carneiro (2010) chega a afirmar que a festa foi (re)inventada pela OVAT, sob novos moldes, para atender a essa demanda turística. Ela cita que um dos principais fundadores da Organização, Elder Camargo dos Passos, registrou em uma de suas obras o papel da OVAT, como uma organização que valoriza as tradições em função do turismo e da renda que gera. Com base nisso, Carneiro (2010) enquadra a Procissão do Fogaréu na teoria destacada na clássica obra de Eric Hobsbawm, como uma (re)invenção da tradição.

Segundo a referida autora, embora a Procissão do Fogaréu seja evocada conforme os moldes atuais como tradição de séculos, não se tem vestígio de sua continuidade após 1745 , quando foi criada. Ela foi retomada apenas em 1967, no mesmo ano em que foi implantado o departamento de turismo no Estado de Goiás. Foi publicado nos diversos jornais do Estado, inclusive $O$ Popular e Folha de Goiás, a seguinte divulgação: "Semana Santa em Goiás terá comemorações em novo estilo"; e em outro jornal a matéria intitulada: "Goiás prepara história ao vivo da Paixão para a Semana Santa". As novidades, a partir daí, foram sendo incorporadas à tradição (re)inventada. O número de visitantes passou a aumentar consideravelmente a cada ano, atingindo seu auge no mesmo período em que o IPHAN introduziu a concepção de patrimônio imaterial.

Tanto a cultura turística como a cultura original da população local se metamorfoseiam durante o encontro entre elas: o turista, no desejo de realizar suas expectativas e fantasias de uma cultura turística, e a população local, que reduz sua visibilidade uma vez que o destaque são seus atrativos turísticos e suas representações. Por isso mesmo, mantém esses atrativos e representações e não medem esforços para que sejam apreciados nos seus aspectos de estética, distinção e singularidade. Acreditando ser uma boa oportunidade e aproveitando de alguns benefícios, essa população favorece o desvio da utilização tradicional do local, a recriação contínua e o embelezamento do local em prol da estética do olhar do turista. O lugar transforma-se para atender o desejo do turista.

Serpa (2007) explica que o turismo faz com que a população local reinvente seu cotidiano, e essa "reinvenção" faz com que as práticas turísticas sobreponham às tradições locais e à própria identidade dos lugares. Esses, por sua vez, recebem novos símbolos, referências, valores e expectativas.

Para os devotos e aqueles que participam, contudo, a fé cristã e suas crenças são o 
que move a realização da procissão. E talvez sejam os principais elementos responsáveis pela sua continuidade como prática sociocultural na cidade.

A festa, portanto, não perde seu sentido original, sua dinâmica é "reinventada" para atender a demanda que se modifica de forma rápida. De acordo com Menezes (2011), a modernidade teve que "reinventar" tradições e romper com a "tradição pura", isto é, aqueles valores radicalmente vinculados ao passado pré-moderno. Neste sentido, a modernidade apresenta descontinuidade, que para Giddens (1991) seria aquela onde os elos sociais têm de ser efetivamente feitos, e não herdados do passado. Persistir, mesmo que se modificando, revela estratégias de sobrevivência da cultura diante de uma lógica capitalista que tudo quer homogeneizar.

\section{Considerações finais}

O mau uso e apropriação indevida dos elementos simbólicos e identitários das populações receptoras constituem em uma tentativa de gerar produtos comercializáveis que ressignificam a própria realidade vivida pelos atores sociais envolvidos, criando um novo valor, um novo olhar, tanto das populações locais sobre si mesmas como dos turistas sobre a cultura alheia. O legado cultural, assim transformado em produto para o consumo, perde seu significado autêntico. A cultura deixa de ser importante por si mesma e passa a ser importante por suas implicações econômicas.

Nessa lógica, as inovações, os eventos culturais e os espetáculos são latentes, muitas vezes resgatados ou recriados, tornando-se o "cartão postal", o principal convite à visita. O encontro entre a cultura e a mercadoria constrói imaginários numa difusão de imagens superficiais que tentam reproduzir o real num processo mercantilizador das singularidades culturais.

$\mathrm{Na}$ lógica do turismo é aceitável e até necessário impor alguns atrativos, recriar ou transformar algo em espetáculo, fazer modificações no que é original para agregar valor, atribuir um sentido exótico ou que cause maior interesse. No entanto, quando a reinvenção da festa parte da imposição da atividade turística, essas ações resultam no estabelecimento de uma nova estrutura socioespacial e de uma ressignificação dos símbolos identitários, sem considerar que os mesmos têm um sentido próprio na memória coletiva local. Na Procissão do Fogaréu, o enfoque sempre é dado à exuberância cênica, e não ao que a representação de fato significa para os fiéis participantes.

Com a turistificação, o lugar assume novas formas e funções, afetando essencialmente as dimensões materiais e simbólicas da sociedade.

Apesar das tendências globais que exercem influência nas dinâmicas locais, as festas ainda manifestam resistência ao processo de globalização que procura homogeneizar todas as práticas socioculturais.

Entende-se que a festa é um importante mecanismo de resistência cultural, pois permite a recuperação da memória histórica, dos valores, das tradições e das formas de vida da comunidade. Mesmo que seja vulnerável à imposição da lógica capitalista, produz na comunidade o desejo de afirmação da própria identidade e, num ciclo de realimentação, estimula o conhecimento sobre seu patrimônio e a uma procura por recuperar cada vez mais seu próprio passado.

O turismo com base na valorização e preservação da cultura, e não na sua exploração comercial, permite que a comunidade se engaje no processo de recuperação da memória cole- 
tiva, de reconstrução da história e de verificação das fontes, fortalecendo os seus sentidos e conexão com o espaço vivido, sua identidade cultural. Problematizar a festa religiosa da Procissão do Fogaréu, enquanto espetáculo, é favorecer a abertura de novas consciências que se contraponham às vertentes economicistas do turismo e reafirmem, nas palavras de Chaveiro (2008a, p.135), "a vida como patrimônio e a cultura como elemento central da vida humana".

\section{Referências bibliográficas}

ALMEIDA. M.G.; VARGAS. M.A.M.; MENDES, G.F. Territórios, paisagens e representações: um diálogo em construção. Mercator, Fortaleza, v. 10, n. 22, p.23-35, mai./ago. 2011.

ALMEIDA. M.G. Diversidades paisagísticas e identidades territoriais e culturais do Brasil sertanejo. In: ALMEIDA, M. G.; CHAVEIRO E. F.; BRAGA, H. C. (orgs.). Geografia e Cultura: os lugares da vida e a vida dos lugares. Goiânia: Vieira, 2008. pp. 47 - 74.

ALMEIDA. M.G. Desenvolvimento turístico ou desenvolvimento local? Algumas reflexões. In: ENTBL - Planejamento para o desenvolvimento local, 2004, Curitiba. Anais... 2004.

ALMEIDA. M.G. Refletindo sobre o lugar turístico no global. In: Turismo com ética. CORIOLANO, L. N. M. T. (orgs.). Fortaleza: UECE, 1998. pp. $122-131$.

ANDRADE, R. B. Práticas sócio-culturais e religiosas: elementos constituintes do lugar. In: ALMEIDA, M. G., CHAVEIRO, E. F., BRAGA, H. C. (orgs.). Geografia e Cultura: a vida dos lugares e os lugares da vida. Goiânia: Vieira, 2008. pp. 22 - 46.

BEZERRA, A. C. A. Cidade, Cultura e Planejamento em Tempo de Espetáculo. In: ENCONTRO NACIONAL DA ANPEGE, 7, 2007a, Niterói. Anais... Niterói: 2007a. 1 CD-ROM.

--BEZERRA, A. C. A. Festa e Identidade: A busca da diferença para o mercado de cidades. In: ARAÚJO, F. G. B., HAESBAERT, R. (orgs.). Identidades e Territórios: questões e olhares contemporâneos. 1. ed. Rio de Janeiro: Access, 2007b. pp. 69 - 92.

CARNEIRO, K. C. A bola da vez. Estudo de caso: uma questão de patrimônio - O turismo e a Cidade de Goiás. Revista Saber Eletrônico, Jussara, ano 1, v. 2. pp. 53-65, setembro, 2010. Disponível em: <http://www.unifaj.edu.br/NetManager/ documentos/A\%20 Bola\%20da\% 20Vez.pdf>. Acesso em 16 dez. 2010.

CASTELLS, M. O Poder da Identidade. 5. ed. São Paulo: Paz e Terra, 2006, v. 2, p. 17-92.

CHAVEIRO, E. F. A cultura como patrimônio e a vida como cultura: disputas de sentidos na Cidade de Goiás - um patrimônio da humanidade. Revista OLAM, Ciência e Tecnologia, Rio Claro, v. 8, n. 1. pp. 122-136, jan/jun, 2008a. Disponível em:<http:// www.periodicos.rc.biblioteca.unesp.br/index.php/olam/article/viewArticle/1238>. Acesso em 16 dez 2010.

CHAVEIRO, E. F. O cerrado em disputa: sentidos culturais e práticas sociais contemporâneas. In: ALMEIDA, M. G.; CHAVEIRO E. F.; BRAGA, H. C. (orgs.). Geografia e Cultura: os lugares da vida e a vida dos lugares. Goiânia: Vieira, 2008b. pp. 75 - 97.

CLAVAL, P. Uma, ou algumas, abordagem (ns) cultural (is) na geografia humana. In: SERPA, A. (org.). Espaços culturais: vivências, imaginações e representações. Salvador: EDUFBA, 2008. pp. $15-29$. 
COSTA, C.L. As festas e o processo de modernização do território goiano. R. RA'E GA, Curitiba: Ed. UFPR, n. 16. pp. 65-71, 2008. Disponível em: <http://ojs.c3sl.ufpr.br/ojs-2.2.4/ index.php/raega/article/view/12679/9917>. Acesso em 22 dez. 2010.

GIDDENS, A. As consequências da modernidade. São Paulo: UNESP, 1991.

MARIANI, A. A Memória Popular no Registro do Patrimônio. In: TRAVASSOS, E. Arte e Cultura Popular. Revista do Patrimônio Histórico e Artístico Nacional. n. 28, 1999.

MENEZES. P.D.L. A (re) invenção do cotidiano: a transformação de festas populares em evento turístico (Estudo de Caso do São João de Campina Grande). CULTUR, ano 06, n. 1, Fev/2012.

PORTAL DA CIDADE DE GOIÁS. Disponível em: <http://www.vilaboadegoias.com.br> Acesso em: 18 nov. 2009.

SANTOS, R. J. (Re) Ocupação do cerrado: novas gentes, outras identidades. In: ALMEIDA, M. G.; CHAVEIRO E. F.; BRAGA, H. C. (orgS.). Geografia e Cultura: os lugares da vida e a vida dos lugares. Goiânia: Vieira, 2008. pp. 98 - 136.

SERPA, A. O espaço público na cidade contemporânea. São Paulo: Contexto, 2007.

Serviço Brasileiro de Apoio às Micro e Pequenas Empresas - SEBRAE. Disponível em: $<$ http://www.sebraego.com.br>. Acesso em 20 jan 2011.

SILVA, A. M. Dossiê de Goiás - Enciclopédia Regional: um compêndio de informações sobre Goiás, sua história e sua gente. Goiânia: Master Publicidade, 2001.

SILVA, M. M. Identidades, culturas, representações festivas e a invenção do folclore em Goiás (1940-1980). Revista Guanicuns, Anicuns, n.2, p.195-210, 2005.

THOMPSON, John B. A mídia e a modernidade: uma teoria social da mídia. Trad. Wagner de Oliveira Brandão. Petrópolis: Vozes, 1998.

\section{Notas}

${ }^{1}$ Disponivel em : http://www.vilaboadegoias.com.br. Acesso em 18 nov. 2009.

Luana Nunes Martins de Lima: Universidade Federal de Goiás, Goiânia, GO, Brasil.

Email: luanunes_7@hotmail.com

Link para o currículo Lattes: http://lattes.cnpq.br/2105017701418889

Data de submissão: 30 de maio de 2012

Data de recebimento de correções: 10 de dezembro de 2012

Data do aceite: 10 de dezembro de 2012

Avaliado anonimamente 